Abstract 287 Table 1 Overian cancer cases $(n=123)$ showing negativetive equivocal and positive result for CA 125 \& HE4

\begin{tabular}{|l|l|l|l|l|l|l|}
\hline CA 123 & HE4 \\
\hline Negative (N) & $\begin{array}{l}\text { Equivocal } \\
\text { (E) }\end{array}$ & Positive (P) & N & E & P \\
\hline \multicolumn{7}{|l|}{ All ovarian cancer cases (pre + post menopausal; n= 123) } \\
\hline 38 & 18 & 67 & 14 & 63 & 45 \\
\hline Premenopausal cases (42/123) & 6 & 26 & 7 & 21 & 14 \\
\hline 10 & 6 & 45 & 7 & 41 & 33 \\
\hline Postmenopausal cases (81/123) & 11 & &
\end{tabular}

negative cases 2/7 showed CA 125 positive result. Mucinous and clear cell variants show HE4 negative result.

Among postmenopausal cases (81/123), 25 showed CA 125 negative where as HE4 was negative in 7/42 cases. 18/25 CA 125 negative cases showed positive HE4 results. None of HE4 negative case showed higher CA 125 value.
Conclusion* Study shows HE is more accurate in diagnosing OC \& differentiating it from benign tumors. The study is continued to achieve a decisive conclusion.

\section{FREQUENCY OF PATHOGENIC MUTATIONS AND PROGNOSTIC IMPACT OF GERMLINE GENE PANEL TESTING IN PATIENTS WITH PRIMARY EPITHELIAL OVARIAN CANCER}

${ }^{1,2}$ B Ataseven*, ${ }^{1} \mathrm{P}$ Harter, ${ }^{3} \mathrm{~K}$ Rhiem, ${ }^{1,4} \mathrm{~F}$ Heitz, ${ }^{1} \mathrm{~S}$ Schneider, ${ }^{1} \mathrm{M}$ Bommert, ${ }^{1} \mathrm{~A}$ Traut, ${ }^{3}$ RK Schmutzler, ${ }^{1} \mathrm{~A}$ Du Bois. 'Evang. Huyssens-Stiftung Essen-Huttrop (eine Einrichtung der KEM | Evang. Kliniken Essen-Mitte gGmbH), Gynaecology and Gynaecologic Oncology, Essen, Germany; '2University Hospital, LMU Munich, Department of Obstetrics and Gynecology; ${ }^{3}$ University Hospital Cologne, Medical Faculty, , Center for Familial Breast and Ovarian Cancer, Center for Integrated Oncology (CIO), , Köln, Germany; ${ }^{4}$ Universitätsmedizin Berlin, corporate member of Freie Universität Berlin, HumboldtUniversität zu Berlin, and Berlin Institute of Health, Berlin, Department for Gynecology with the Center for Oncologic Surgery Charité Campus Virchow-Klinikum, Berlin

10.1136/ijgc-2021-ESGO.379

Abstract 291 Table 1 Univariate and multivariate analysis of prognostic factors for overall survival (OS)

\begin{tabular}{|c|c|c|c|c|c|c|c|}
\hline \multirow[t]{2}{*}{ OS } & \multirow[t]{2}{*}{ Total } & \multirow[t]{2}{*}{ Events } & \multirow[t]{2}{*}{ Median OS } & \multicolumn{2}{|c|}{ Univariate } & \multicolumn{2}{|c|}{ Multivariate } \\
\hline & & & & HR (Cl95\%) & $P$ & HR (Cl95\%) & $P$ \\
\hline $\mathrm{n}$ & 569 & 140 & 55 & & & & \\
\hline \multicolumn{8}{|l|}{ Type of surgery } \\
\hline PDS & $413(72.6)$ & $93(22.5)$ & 61 & 1 (ref.) & & 1 & \\
\hline IDS & $156(27.4)$ & $47(30.1)$ & 40 & $2.09(1.45-3.00)$ & $<0.001$ & $2.79(1.86-4.19)$ & $<0.001$ \\
\hline \multicolumn{8}{|c|}{$\begin{array}{l}\text { ECOG performance } \\
\text { status }\end{array}$} \\
\hline 0 & $543(95.4)$ & $133(25.4)$ & 55 & 1 & & 1 & \\
\hline$\geq 1$ & $26(4.6)$ & $7(26.9)$ & 25 & $1.96(0.91-4.20)$ & 0.084 & $1.35(0.59-3.12)$ & 0.474 \\
\hline \multicolumn{8}{|l|}{ Albumin (g/L) } \\
\hline$\geq 35$ & $470(82.6)$ & $112(23.8)$ & 55 & 1 & & 1 & \\
\hline$<35$ & $46(8.1)$ & $16(34.8)$ & 44 & $1.68(0.99-2.84)$ & 0.053 & $1.25(0.70-2.23)$ & 0.449 \\
\hline unknown & $53(9.3)$ & $12(22.6)$ & 71 & & & $0.50(0.26-0.95)$ & 0.035 \\
\hline \multicolumn{8}{|l|}{$\mathrm{ACCl}$} \\
\hline $0-1$ & $248(43.6)$ & $59(23.8)$ & 60 & 1 & & 1 & \\
\hline $2-3$ & 248(43.6) & $60(24.2)$ & 55 & $1.18(0.83-1.70)$ & 0.358 & $1.11(0.76-1.60)$ & 0.589 \\
\hline$\geq 4$ & $73(12.8)$ & $21(28.8)$ & 36 & $1.79(1.09 .2-95)$ & 0.022 & $1.58(0.96-2.62)$ & 0.074 \\
\hline \multicolumn{8}{|l|}{ Ascites (mL) } \\
\hline$\leq 500$ & $431(75.7)$ & $93(21.6)$ & 62 & 1 & & 1 & \\
\hline$>500$ & $138(24.3)$ & $47(34.1)$ & 43 & $1.90(1.34-2.71)$ & $<0.001$ & $1.75(1.14-2.68)$ & 0.010 \\
\hline \multicolumn{8}{|c|}{ History of previous } \\
\hline no cancer & $492(86.5)$ & $121(24.6)$ & 55 & 1 & & 1 & \\
\hline breast cancer & $41(7.2)$ & $8(19.5)$ & 76 & $0.77(0.38-1.57)$ & 0.474 & $0.74(0.34-1.62)$ & 0.454 \\
\hline $\begin{array}{l}\text { other type of } \\
\text { cancer }\end{array}$ & $36(6.3)$ & $11(30.6)$ & 39 & $1.49(0.80-2.76)$ & 0.211 & $1.39(0.70-2.75)$ & 0.340 \\
\hline \multicolumn{8}{|c|}{$\begin{array}{l}\text { Residual disease } \\
\text { after surgery (mm) }\end{array}$} \\
\hline RD0 & $422(74.2)$ & $80(19)$ & 71 & 1 & & 1 & \\
\hline $\mathrm{RD} \geq 1$ & $147(25.8)$ & $60(40.8)$ & 36 & $2.81(2.01-3.94)$ & $<0.001$ & $2.87(1.99-4.14)$ & $<0.001$ \\
\hline \multicolumn{8}{|l|}{ FIGO } \\
\hline FIGO III & $261(45.9)$ & $48(18.4)$ & 76 & 1 & & 1 & \\
\hline FIGO IV & $308(54.1)$ & $92(29.9)$ & 47 & $1.79(1.26-2.55)$ & 0.001 & $1.27(0.87-1.26)$ & 0.217 \\
\hline \multicolumn{8}{|l|}{ Germline result } \\
\hline No mutation & $430(75.6)$ & $115(26.7)$ & 47 & 1 & & 1 & \\
\hline BRCA1/2mut & 108(19) & $20(18.5)$ & - & $0.49(0.30-0.78)$ & 0.003 & $0.49(0.31-0.80)$ & 0.004 \\
\hline Other mutation & $31(5.4)$ & $5(16.1)$ & 71 & $0.44(0.18-1.08)$ & 0.074 & $0.34(0.14-0.85)$ & 0.021 \\
\hline
\end{tabular}


Introduction/Background* The detection of gBRCA1/2 mutations in patients (pts) with epithelial ovarian cancer (EOC) provides information regarding family risk and influences clinical management, e.g. use of PARP inhibitors. The availability of next generation sequencing (NGS) allows for simultaneous sequencing of multiple cancer risk genes including BRCA1/2. Our aim was to evaluate the prevalence and clinical outcome of deleterious germline mutations in EOC patients.

Methodology EOC patients treated between 2011 and 2020 at our institution and with germline TruRisk ${ }^{\circledR}$ gene panel testing were included in this retrospective analysis. Based on the genetic test result three cohorts were considered: A) no mutation, B) gBRCA1/2, and C) mutations in other risk genes. Demographic and clinicopathological characteristic were retrieved from the prospective database. To evaluate survival outcome in FIGO III/IV EOC univariate and multivariate logistic regression was performed.

Result(s)* In total 702 EOC pts underwent germline panel testing. Median age was 59 years, $74.5 \%$ underwent primary debulking surgery, $83.9 \%$ were FIGO III/IV, and complete macroscopic resection was achieved in $74.0 \%$. No mutation was detected in $76.6 \%(\mathrm{n}=538)$, pathogenic gBRCA1/2 mutations in $17.4 \%(n=122)$, and mutations in other risk genes in $6.0 \% \quad(n=42)$, respectively (tbl.1). Significant differences between the cohorts were detected for age, pervious history of malignancies, personal/familial breast/ovarian cancer history, and histology.

For FIGO III/IV patients median PFS was significantly different for cohort $\mathrm{A}, \mathrm{B}$, and $\mathrm{C}$ with 23, 37, and 34 months $(\mathrm{p}=0.059 /$ multivariate 0.015$)$, respectively. 3-years-OS was $70 \%, 83 \%$, and $87 \%$ for cohorts $\mathrm{A}, \mathrm{B}$, and C ( $\mathrm{p}=0.003)$, respectively.

In multivariate analysis type of surgery (IDS: HR 2.79 (1.86-4.19), $\mathrm{p}<0.001)$,) ascites $>500 \mathrm{~mL}(\mathrm{HR} 1.75(1.14-2.68)$, $\mathrm{p}=0.010)$, and residual disease $(\mathrm{RD}>0 \mathrm{~mm}$ : HR 2.87(1.994.14), $\mathrm{p}<0.001)$, were identified as worse prognostic factors for OS. Patients from cohorts B and C showed significantly better OS than those from cohort A (B: HR 0.49(0.31-0.80), $\mathrm{p}=0.004$; C: HR 0.34(0.14-0.85), $\mathrm{p}=0.021$ ) (table 1, figure 1). Conclusion* The detection rate of germline mutations in EOC is $23.4 \%$. Our findings underline the necessity to offer germline panel testing in EOC to identify families at risk. Further,

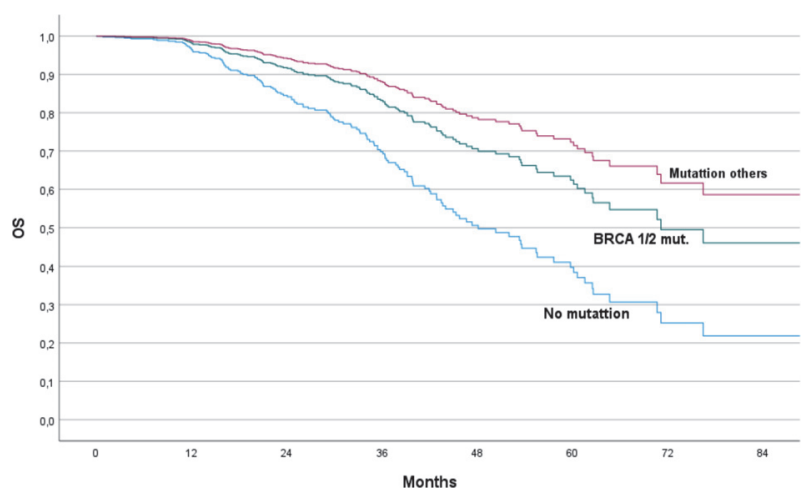

Abstract 291 Figure 1 Overall survival in patients with EOC undergoing cytoreductive surgery broken-down by gene panel analysis/ pathogenic mutation status our findings underscore the prognostic value of germline mutations towards a better prognosis.

\section{ADVANTAGES OF LIGASURE ${ }^{\circledR}$ MARYLAND JAW OPEN SEALER/DIVIDER WITH NANOCOATING ON CYTOREDUCTIVE SURGERY IN WOMEN WITH ADVANCED OVARIAN CANCER}

D Tsolakidis, E Markopoulou, K Chatzistamatiou*, D Zouzoulas, P Ioannidou, E Zioga, M Tsoukaki, S Tsiapakidou, A Kalpatsanidis, E Savidou, E Margaritidou, E Mpili, T Mikos, G Grimbizis. Papageorgiou Hospital, Aristotle University of Thessaloniki, 1st Department of Obstetrics and Gynecology, Thessaloniki, Greece

\subsection{6/ijgc-2021-ESGO.380}

Introduction/Background* Cytoreductive surgery is the cornerstone treatment in the armamentarium for women with advanced ovarian cancer. The goal of successful cytoreduction is achiving no visible tumor or residual disease less than 1 $\mathrm{cm}$. This prerequisite is a demanding process with high morbidity, requiring high clinical expertise and enhanced surgical skills. The objective of the presented analysis is to identify whether the usage of the Ligasure ${ }^{\circledR}$ Maryland jaw open sealer/ divider (LMjsd) with nanocoating facilitates cytoreductive surgery by reducing intraoperative bleeding and hence other parameters regarding hospitalization.

Methodology Women with advanced stage ovarian cancer (stage III or IV) who were referred to the Department of Gynecologic Oncology, 1st Department of Obstetrics and Gynecology, Papageorgiou General Hospital, Thessaloniki, Greece, and were subjected to either primary or interval cytoreductive surgery were included in the analysis. Women, who were operated on by the same group of Gynecologic Oncologists, were retrospectively allocated into two distinct groups comprised of women subjected to surgery with or without using the LMjsd. The analysis focused on differences between the two groups regarding intraoperative blood loss and blood transfusion, duration of surgery, blood transfusion within the post-operative course, Intensive Care Unit (ICU) and overall hospital length of stay.

Result(s)* Between 2012 and 2020, 284 women with ovarian cancer were subjected to surgery; of these, 208 had ovarian cancer stage III or IV. In the group of women $(\mathrm{N}=34)$, who were operated on using the LMjsd, duration of surgery, and blood loss during surgery were significantly decreased $(\mathrm{p}<0.0005$ for both parameters) compared to cases treated without the LMjsd $(\mathrm{N}=174)$. The intra-operative blood transfusion rate and the number of units of packed red blood cells given to the patients were significantly decreased in the first group $(p=0.0025)$, whereas post-operative blood transfusion rate was not affected $(p=0.065)$. Moreover, ICU and overall hospital length of stay were significantly decreased in cases where the LMjsd was used $(\mathrm{p}<0.0005$ and $\mathrm{p}=0.015)$.

Conclusion* The LMjsd with nanocoating reduces intra-operative bleeding and transfusion rates, and improves duration of surgery, and ICU and overall hospital length of stay in women subjected to cytoreductive surgery for advanced ovarian cancer. 